\title{
Bactericidal activity and biocompatibility of crossark ceragenin-coated magnetic nanoparticles
}

\author{
Katarzyna Niemirowicz ${ }^{1 *}$, Urszula Surel ${ }^{1}$, Agnieszka Z Wilczewska², Joanna Mystkowska ${ }^{3}$, Ewelina Piktel ${ }^{1}$, Xiaobo Gu ${ }^{6}$, \\ Zbigniew Namiott ${ }^{4}$ Alina Kułakowska ${ }^{5}$, Paul B Savage ${ }^{6}$ and Robert Bucki ${ }^{1,7}$
}

\begin{abstract}
Background: Ceragenins, synthetic mimics of endogenous antibacterial peptides, are promising candidate antimicrobial agents. However, in some settings their strong bactericidal activity is associated with toxicity towards host cells. To modulate ceragenin CSA-13 antibacterial activity and biocompatibility, CSA-13-coated magnetic nanoparticles (MNP-CSA-13) were synthesized. Transmission electron microscopy (TEM), Fourier transform infrared spectroscopy (FT-IR), differential scanning calorimetry (DSC) and thermogravimetric analysis (TGA) were used to characterize MNP-CSA-13 physicochemical properties. Bactericidal action and ability of these new compounds to prevent Pseudomonas. aeruginosa biofilm formation were assessed using a bacteria killing assay and crystal violet staining, respectively. Release of hemoglobin from human red blood cells was measured to evaluate MNP-CSA-13 hemolytic activity. In addition, we used surface activity measurements to monitor CSA-13 release from the MNP shell. Zeta potentials of $P$. aeruginosa cells and MNP-CSA-13 were determined to assess the interactions between the bacteria and nanoparticles. Morphology of $P$. aeruginosa subjected to MNP-CSA-13 treatment was evaluated using atomic force microscopy (AFM) to determine structural changes indicative of bactericidal activity.

Results: Our studies revealed that the MNP-CSA-13 nanosystem is stable and may be used as a pH control system to release CSA-13. MNP-CSA-13 exhibits strong antibacterial activity, and the ability to prevent bacteria biofilm formation in different body fluids. Additionally, a significant decrease in CSA-13 hemolytic activity was observed when the molecule was immobilized on the nanoparticle surface.
\end{abstract}

Conclusion: Our results demonstrate that CSA-13 retains bactericidal activity when immobilized on a MNP while biocompatibility increases when CSA-13 is covalently attached to the nanoparticle.

Keywords: Antibacterial activity, Pseudomonas aeruginosa, Ceragenins, Magnetic nanoparticles

\section{Background}

Ceragenin CSA-13 belongs to family of synthetic mimics of cationic antimicrobial peptides (CAPs) that display strong antibacterial activities [1,2]. Cationic lipids such as CSA-13 are easier to prepare and purify than antimicrobial peptides [3]. They are also resistant to digestion by proteases that are commonly present at infection sites [4]. Numerous reports describe CSA-13 activity against multidrug-resistant bacteria, lipid-enveloped viruses and parasites $[3,5,6]$. The mechanism of CSA-13 action involves direct interaction with negatively charged bacterial membrane molecules including lipopolysaccharide and

\footnotetext{
* Correspondence: mikro.nano@umb.edu.pl

'Department of Microbiological and Nanobiomedical Engineering, Medical

University of Bialystok, Mickiewicza 2c, 15-222 Bialystok, Poland

Full list of author information is available at the end of the article
}

phosphatidylglycerol, which results in membrane permeabilization $[7,8]$. However, CSA-13's ability to compromise lipid organization in bacterial membranes is not completely selective, and, at higher concentrations, CSA-13 can affect the lipid organization within host cell membranes, which in the case of RBCs leads to hemolysis $[7,8]$. Methods intended to reduce potential harmful effects of CSA-13 and other ceragenins are provided by nanotechnology strategies and the use of nanoparticles as drug delivery systems (DDS) $[9,10]$. Generally, this approach may prove beneficial in providing a larger therapeutic window (i.e., the difference in effective $v s$. toxic concentrations). Among many types of nanoparticles, magnetic nanoparticles (MNPs) are one of the most promising materials in nanomedicine [11]. They can be delivered to a specific area via a magnetic field [12-14]. 
Targeting provided by nanoscale-based drug delivery limits and helps control drug toxicity. Additionally, MNP surface functionalization provides the opportunity to attach different active molecules such as drugs or homing ligands and combine diagnostic and therapeutic activities within the same structure [15]. In this study, we developed a novel magnetic nanosystem made out of an iron oxide core, aminosilane layer and CSA-13. Our results suggest that immobilization of CSA-13 on the MNP surface significantly reduces membrane toxicity to $\mathrm{RBCs}$ and increases antimicrobial activity against selected bacteria.

\section{Results and discussion}

The synthesis of MNP-CSA-13 and the surface modification process is shown in Figure 1. The MNP magnetic core was obtained following a modification of Massart's method [16]. After formation, magnetic nanoparticles were treated with (3-aminopropyl)trimethoxysilane (APTMS) to link the amino-terminated silica to their surface. Then amine functionalized silica nanospheres were treated with glutaraldehyde, to obtain a platform for CSA-13 immobilization. The terminal aldehyde groups from this surface are able to react with the primary amine groups of CSA-13. This reaction results in an imine bond between the surface and CSA-13. We anticipate that amine group at the $\mathrm{C} 3$ position in CSA-13 is the primary site of reactivity because it is less sterically hindered than other amines in the molecule. Imine formation for CSA-13 immobilization was selected because treatment of imines with an excess of water leads to their hydrolysis back to an aldehyde and an amine, especially in the presence of acid. During infection and inflammation a decrease of the $\mathrm{pH}$ frequently occurs $[17,18]$. Therefore, MNP-CSA-13 could be used as carriers for controlled antibiotic delivery to kill microorganisms at infection sites where the $\mathrm{pH}$ is usually less than $6[19,20]$. The release of CSA-13 from MNP-CSA-13, subjected to a magnetic field, was assessed by measuring the increase of

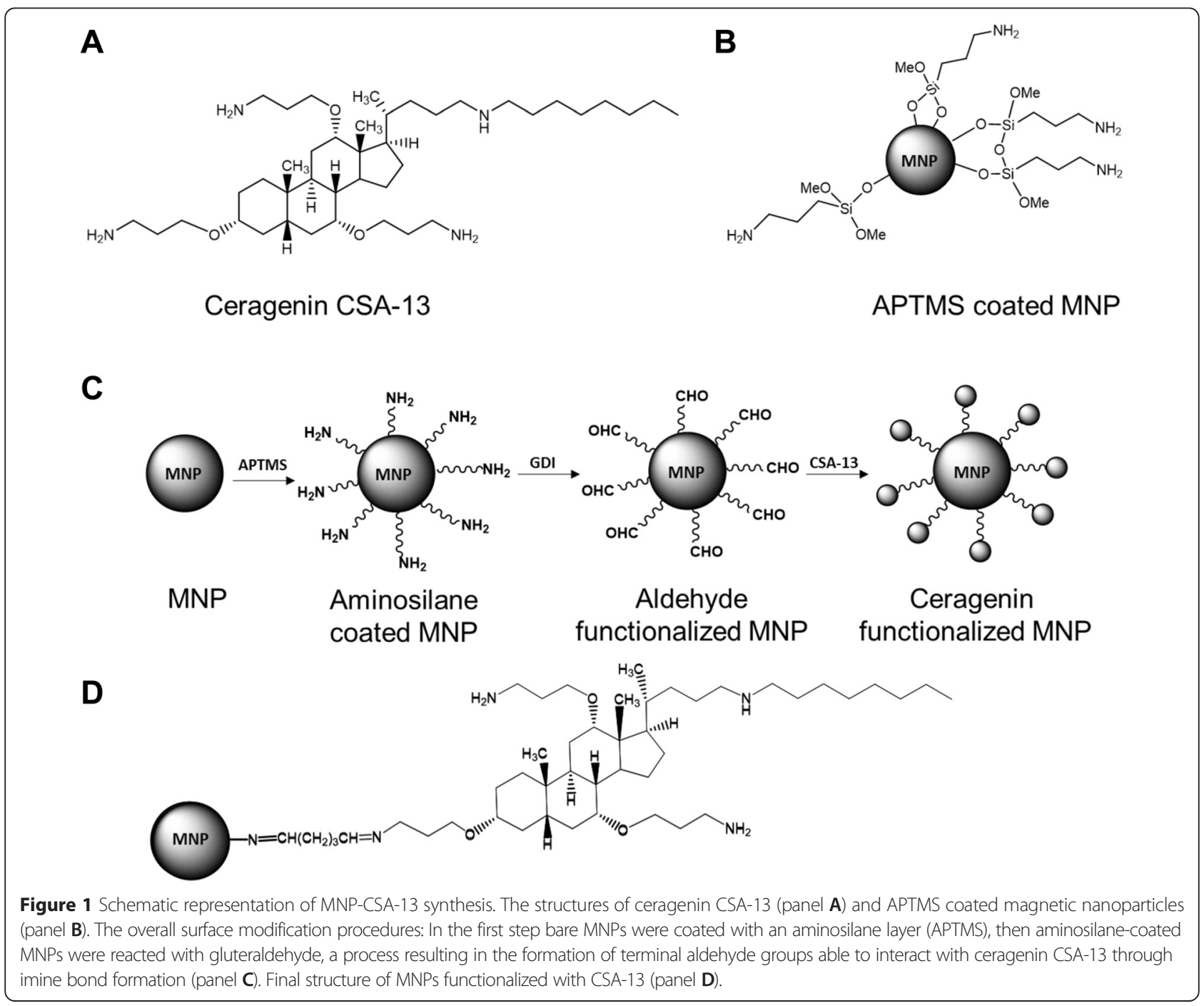


surface tension. As CSA-13 is released the surface tension is altered (Figure 2). The release rate was expected to depend on local $\mathrm{pH}$, and over a one hour a much slower release rate was observed at $\mathrm{pH} 7.4$ (10\% release) as compared to $\mathrm{pH} 5$ (25\% release). We did not observe differences between intrinsic surface activity of CSA-13 at $\mathrm{pH}$ 7.4 and 5 (data not shown). We conclude that lower $\mathrm{pH}$ accelerates imine bond hydrolysis, liberating CSA-13 from the nanoparticle. It is worth noting that rapid CSA-13 release during the first 20 minutes is potentially due to a burst effect [21]. The ability to control CSA-13 release from nanoparticles in a low $\mathrm{pH}$ indicates a potential benefit of using this nanosystem in eradication of Helicobacter pylori. High susceptibility of $H$. pylori to CSA-13 was previously described [22]. Moreover, the observed burst effect of CSA-13 release may be useful for certain applications, especially for wound treatment, targeted delivery and pulsatile release [23].

Figure 3A shows FT-IR spectra (A - C) for aminosilane-, glutaraldehyde- and ceragenin-functionalized magnetic nanoparticles $\quad\left(\mathrm{MNP} @ \mathrm{NH}_{2} ; \quad \mathrm{MNP} @ \mathrm{NH}=\mathrm{CH}\left(\mathrm{CH}_{2}\right)_{3} \mathrm{CHO}\right.$; MNP-CSA-13 respectively). The curve D represented FT-IR spectrum of unbound CSA-13. The existence of a magnetic core in all samples is indicated by a band at $\sim 550 \mathrm{~cm}^{-1}$, which corresponds to the $\mathrm{Fe}-\mathrm{O}$ stretching mode of $\mathrm{Fe}_{3} \mathrm{O}_{4}$. The spectrum of $\mathrm{MNP} @ \mathrm{NH}_{2}$ shows a broad band at $1000-1090 \mathrm{~cm}^{-1}$ associated with $\mathrm{Si}-\mathrm{O}, \mathrm{Si}-\mathrm{O}-\mathrm{Si}$ and $\mathrm{Fe}-\mathrm{O}-\mathrm{Si}$ stretching vibrations. In all samples, the bands around $1557 \mathrm{~cm}^{-1}$ and above $3300 \mathrm{~cm}^{-1}$ correspond to N-H bending and stretching vibrations, respectively. After functionalization with glutaraldehyde the stretching vibration of the

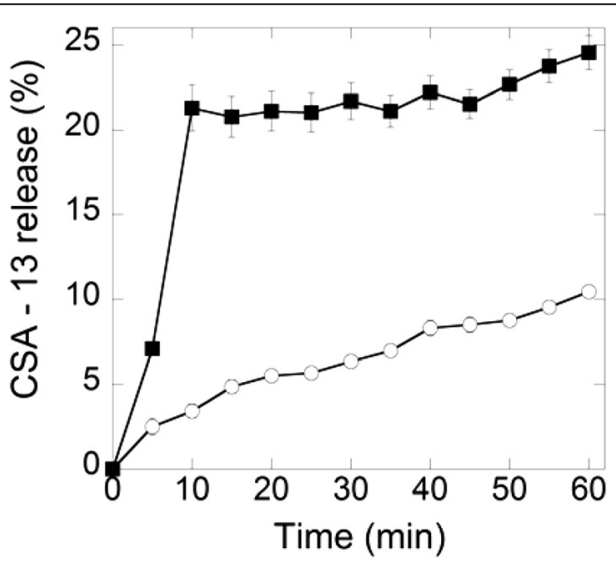

Figure $2 \mathrm{pH}-$ dependent release of CSA-13 from MNP-CSA-13. CSA-13 release (hydrolysis of imine bond) was monitored by recording changes of surface tension at an air-water interface of a MNP-CSA-13 suspension. A rapid increase of CSA-13 release during the first 10 minutes after placing MNP-CSA-13 in a low pH buffer $(\mathrm{pH}=5)$ was observed (black squares). After this time the shape of the curves indicates further gradual release. On the other hand, at $\mathrm{pH}=7.4$, slow, but progressive release of CSA-13 molecules from MNP-CSA-13 was observed (white circles). Data represent mean \pm SD from 3 experiments.
$\mathrm{C}=\mathrm{O}$ bond around $1654 \mathrm{~cm}^{-1}$ was recorded. CSA-13 attachment to the MNP surface was detected by a band at $1738 \mathrm{~cm}^{-1}$, which corresponds to the imide stretching band. Additionally, the imide in-plane stretching bands were found at $1564 \mathrm{~cm}^{-1}$. The presence of $\mathrm{C}-\mathrm{H}$ stretching modes around $2930 \mathrm{~cm}^{-1}$ and $2850 \mathrm{~cm}^{-1}$ associated with implemented ethyl and alkyl groups further confirm the presence of a silica shell on the MNP surface and CSA-13 functionalization. The characteristic band for free CSA-13 was present within MNP-CSA-13, indicating that CSA-13 molecules were immobilized on the nanocomposite surface.

The thermal properties of MNP-CSA-13 were characterized by differential scanning calorimetry (DSC) (Figure 3B). The heating curves of aminosilane- and glutaraldehydeand ceragenin-functionalized MNPs indicates differences in the chemical nature of coating. At temperatures higher than $150^{\circ} \mathrm{C}$ the breakdown of the organic skeleton (decomposition of methoxyl and propylamine groups) was observed in the DSC curve of $\mathrm{MNP} @ \mathrm{NH}_{2}$ (empty circles). Analysis of the curves for glutaraldehyde functionalized MNPs (gray squares) and CSA-coated MNP (black triangles) indicate that these peaks can't be distinguished, which can be explained by the functionalization of the aminosilane surface by glutaraldehyde and ceragenin respectively. In the curve for glutaraldehyde- and CSA-13functionalized MNPs, a large endothermic transition was found from 150 to $400^{\circ} \mathrm{C}$. Additionally, a high endothermic peak for MNP-CSA-13 at $235^{\circ} \mathrm{C}$ was observed. Figure 3 panels $C$ and $D$ show the thermogravimetric analysis results for the aminosilane-, glutaraldehyde-, and CSA-13functionalized magnetic nanoparticles, respectively. Bare MNP shows $6 \%$ weight loss in the temperature range $50-800^{\circ} \mathrm{C}$, which is directly associated with the removal of adsorbed water and decomposition of hydroxyl surface groups [24]. The thermogravimetric analysis curves (Figure 3C) show that the weight loss for aminosilaneand glutaraldehyde-coated MNPs during the performed analysis is about $8 \%$. Curve comparison of glutaraldehyde modified MNPs and aminosilane modified MNPs, (Figure 3D), revealed a characteristic peak at $570^{\circ} \mathrm{C}$. After glutaraldehyde decomposition, the shape of both curves did not differ. The thermogravimetric analysis of CSA-13 functionalized MNPs (Figure 3C) showed a total weight loss of $35 \%$. The $14 \%$ weight loss of the MNPCSA-13 (compared to the weight loss of bare and $\mathrm{MNP} @ \mathrm{NH}_{2}$ ) indicated successful CSA-13 immobilization on the MNP surface, with 14\% CSA-13 content. For MNP-CSA-13, we observed two decomposition peaks, with the first at $240^{\circ} \mathrm{C}$ and the second at $400^{\circ} \mathrm{C}$ (Figure 3D). A second peak indicated decomposition of the aminosilane layer, which was recorded for all analyzed samples. Based on weight lost and total amount of amine group on the MNP surface, we calculated that the number of CSA13 molecules was $3.53 \times 10^{13}$, which corresponds to a 
A

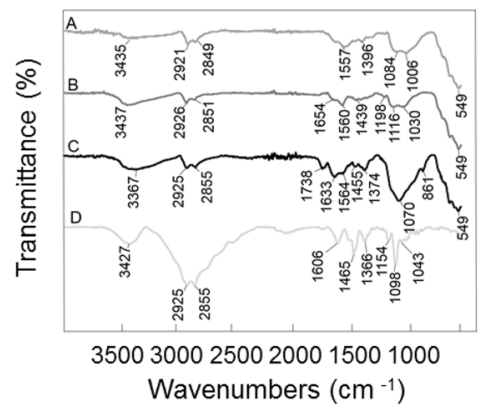

C

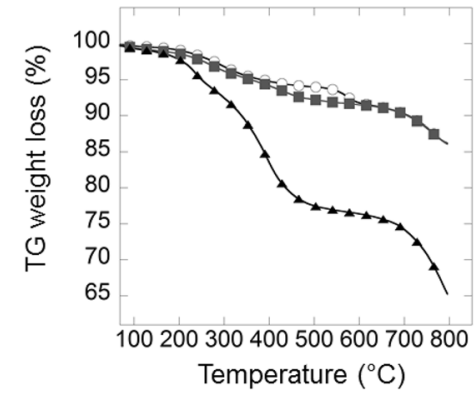

B

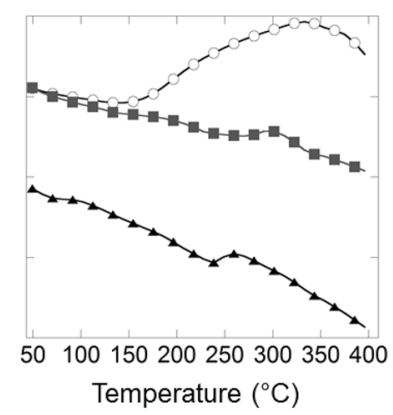

D

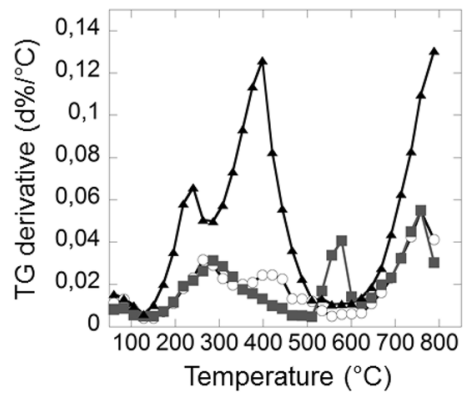

Figure 3 Physicochemical properties of synthesized magnetic nanoparticles. ATR FT-IR spectra of the aminosilane- (curve A), glutaraldehyde - (curve B), CSA-13 (curve C) functionalized MNPs and free CSA-13 (curve D) (panel A). Panels B-D show thermal properties of aminosilane- (light gray circle line), glutaraldehyde - (square gray line) and CSA-13 (triangle black line) functionalized MNPs. Differential scanning calorymetry analysis curves, thermogravimetric analysis curves and differential thermal analysis represent panels $\mathbf{B}, \mathbf{C}$ and $\mathbf{D}$ respectively. Data from one experiment performed in triplicate are shown.

number of molecules 20 times lower per $\mu \mathrm{g}$ present than in the original volume of CSA-13 solution used for MNP functionalization.

A relatively narrow size distribution of magnetic nanoparticles functionalized with CSA-13 is shown in Figure 4. Particles were spherical with a diameter as determined from the TEM image of $14 \mathrm{~nm} \pm 2 \mathrm{~nm}$ (the size was calculated using 100 randomly selected particles). Nanoparticles should be well separated due to the repulsion between CSA-13 molecules in the coating layer, but the observed MNPs clusters can be explained by the drying process in the preparation for TEM measurements. When compared to previously characterized amino- functionalized MNPs, the size of CSA-13 functionalized MNPs did not significantly differ [25]. Additionally, the accuracy of TEM size analysis was in agreement with XRD analysis (data not shown) [25].

$P$. aeruginosa is an opportunistic pathogen that frequently causes hospital infection, affecting mostly immunocompromised patients and those suffering from cystic fibrosis [26,27]. Using physicochemical evaluation, the total amount of CSA-13 on the MNPs surface was
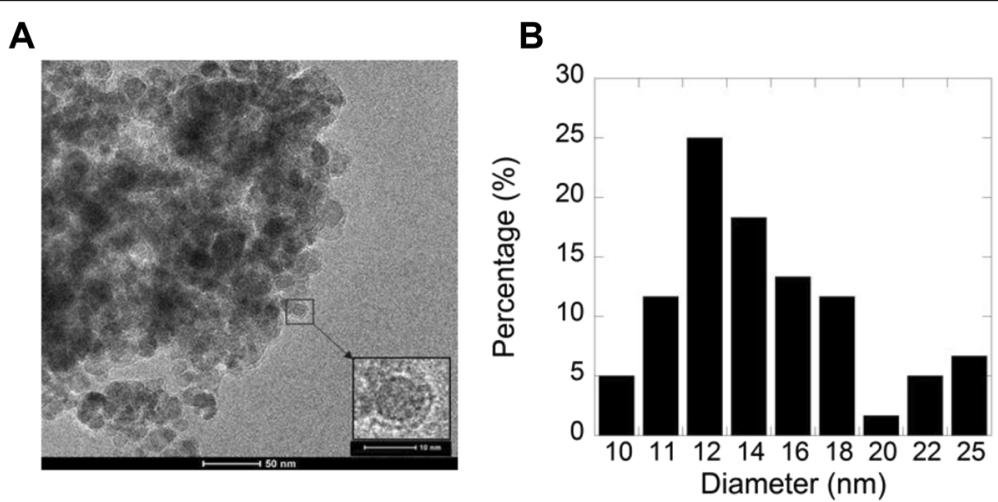

Figure 4 Transmission electron microscopy (TEM) images of MNP-CSA-13. Transmission electron microscopy images (pane $\mathbf{A}$ ) and size distribution (panel B) of MNP-CSA-13. Ceragenin-loaded magnetic nanoparticles had an iron oxide core of $9 \pm 2 \mathrm{~nm}$. MNP functionalization with CSA-13 results in a MNP size increase. Data from one experiment performed in triplicate are shown. 
determined and bactericidal activity of an equal CSA-13 concentration (free CSA-13 and CSA-13 attached to MNPs) per $\mathrm{ml}$ were compared. Figure $5 \mathrm{~A}$ shows that immobilization of CSA-13 on the nanoparticle surface did not affected its antibacterial activity against $P$. aeruginosa, and this observation is in agreement with a previous study where CSA-13 in combination with pluronic acid was tested [28]. Bactericidal activity against clinical isolates of $P$. aeruginosa strains shows that more than $60 \%$ of bacteria were killed using a $1 \mu \mathrm{g} / \mathrm{ml}$ dose, and at concentration of $10 \mu \mathrm{g} / \mathrm{ml}$ no bacteria growth was observed (Figure 5C). Interestingly, a dose-dependent decrease of bacteria growth was observed for uncoated MNPs, with a $80 \%$ decrease at $100 \mu \mathrm{g} / \mathrm{ml}$. The decline of $P$. aeruginosa Xen 5 chemiluminescence after treatment with MNP-CSA-13 is shown in Figure 5D. Comparison of bacteria luminescence after MNP-CSA-13 addition suggests that the nanocomposite is more efficient in killing bacteria than CSA-13 alone. The decrease of chemiluminescence, which indicates the ability of MNP-CSA-13 to affect bacteria metabolism, reached up to $70 \%$, as compared to colistin ( 24\%), and unfunctionalized MNPs $(\sim 40 \%)$. These data support the hypothesis that a synergistic effect of MNPs and CSA-13 might exist. Novel formulations using lipids and polymeric nanostructures for delivery of antimicrobial agents may be useful in other applications as well [29]. A magnetic drug delivery system was previously proposed for antibiotics such as chloramphenicol (successfully loaded into OA/SDS-coated MNPs) [30], nystatin [31] and streptomycin [24], both loaded on chitosan coated MNPs; however, the attaching process was achieved by chemical adsorption, based on nonspecific electrostatic or hydrophobic interactions. The covalent immobilization of antibiotics proposed here possesses some advantages compared to chemical adsorption. Recent reports show that immobilization of antimicrobial peptides (AMPs) onto a biomaterial surface helps to avoid AMP limitations, such as short half-life and toxicity associated with higher concentrations of soluble peptides [32]. Additionally, Zhao et al. argued that advantages of attachment by chemical reaction also include low incidence of side effects and non-accumulation in tissues (brain, liver and spleen) [33]. Moreover, covalent bonding allows the $\mathrm{pH}$-depending control of substance release, due to the mechanism of the hydrolysis reaction [34].

Bacteria growth in biofilm form is associated with increased resistance to antibiotic treatment. Additionally, biofilm plays a key role in chronic Pseudomonas infections [35-37]. Therefore, new approaches to prevent biofilm formation are of great interest. As indicated in
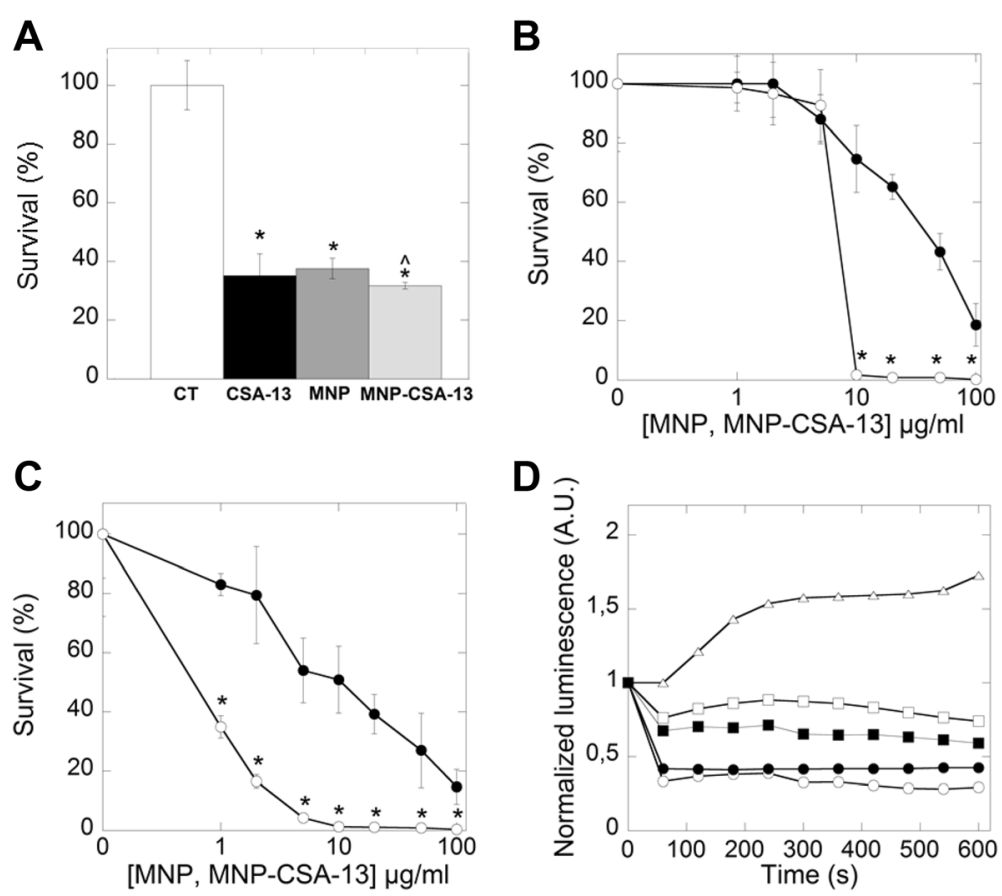

Figure 5 Bactericidal activity of MNP@CSA-13 against $P$. aeruginosa strains. Bactericidal activity of CSA-13 (0.7 $\mu \mathrm{g} / \mathrm{ml}), \mathrm{MNPs}(4.3 \mu \mathrm{g} / \mathrm{ml})$ and MNP-CSA-13 $(5 \mathrm{\mu g} / \mathrm{ml})$ against $P$. aeruginosa PAO14 (CT - control) (panel A). To compare antibacterial potential of MNP, CSA-13 and MNP-CSA-13 against $P$. aeruginosa, CSA-13 concentration was estimated based on physicochemical data and yield of reaction. Panels $\mathbf{B}$ and $\mathbf{C}$ show survival of PAO1 and a clinical strain of $P$ aeruginosa isolated from cystic fibrosis sputum in the presence of MNPs (black circles) and MNP-CSA-13 (white circles) respectively. Reduction of $P$.

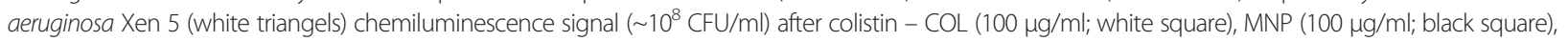
CSA-13 (100 $\mu \mathrm{g} / \mathrm{ml}$; black circles) and MNP-CSA-13 $(100 \mu \mathrm{g} / \mathrm{ml}$; white circles) addition - panel D. Data represent mean \pm SD, $\mathrm{n}=3$ with * statistical significance compared to untreated bacteria cells $(p \leq 0.05) ; \wedge$ statistical significance compared to bacteria treated with free CSA-13 ( $p \leq 0.2)(p a n e l \mathbf{A})$. 
Figure 6 MNP-CSA-13 was able to prevent biofilm formation and effectively kill bacteria embedded into the biofilm matrix. At MNP-CSA-13 concentration of $1 \mu \mathrm{g} / \mathrm{ml}$, biofilm formation decreased by $\sim 40 \%$. Total reduction of adhesion of $P$. aeruginosa on a polystyrene surface was observed at a concentration of $100 \mu \mathrm{g} / \mathrm{ml}$. A similar effect was obtained for both tested $P$. aeruginosa strains (PAO1 and a selected clinical strain). Collected results are strongly supported by a recent study showing that CSA13 is active against bacteria forming biofilms. Previous reports indicate that more than $50 \%$ of bacteria cells in such networks were killed at $50 \mu \mathrm{g} / \mathrm{ml}$. Total reduction of live bacteria cells was observed with the concentration of $100 \mu \mathrm{g} / \mathrm{ml}$ [38]. Additionally, another study shown that CSA-13 inhibits the adhesion of $P$. aeruginosa to an abiotic surface and reduces biofilm mass [39]. Our results indicate that MNP-CSA-13 is useful in preventing bacteria biofilm formation, and it may have higher activity than previously described nanosystems [40]. Iron oxide nanoparticles coated by a carboxylate shell at a concentration of $1000 \mu \mathrm{g} / \mathrm{ml}$ were able to kill up to $33 \%$ of $S$. aureus after initial biofilm formation over a 24 hour time period [40]. Similarly, another study demonstrated significant reduction in biofilm growth for $S$. aureus and P. aeruginosa in the presence of iron oxide and gold nanoparticles at a concentration range 50-150 $\mu \mathrm{g} / \mathrm{ml}$ [41]. Hetric et al. revealed that nitric-oxide releasing silica nanoparticles strongly inhibit biofilm formation by Gram-negative and Gram-positive bacteria [42]. Abdelghany et al. showed that gentamycin-loaded polylactide-co-glycolide nanoparticles possess excellent potential against a pre-formed $P$. aeruginosa biofilm [43].

The toxicity attributed to AMPs is frequently correlated to high concentrations used to compensate for their relatively short half-life due to rapid protease digestion or aggregate formation [44,45]. Ceragenins, including CSA13 , are likely cause red blood cell ( $\mathrm{RBC}$ ) hemolysis at high concentrations as a consequence of their membrane activity. This effect is caused by membrane destruction after insertion $[46,47]$. An understanding of the mechanisms governing magnetic nanoparticle interactions with $\mathrm{RBC}$ membranes is necessary to create an optimal nanosystem for medicinal applications [48]. Data in Figure 7A indicate that MNP-CSA-13 did not affect RBC membrane permeability at a concentration range of $1-100 \mu \mathrm{g} / \mathrm{ml}$. This concentration range of the nanoparticles effectively kills planktonic $P$. aeruginosa as well as the bacteria in a mature biofilms. This result suggests that attachment of CSA-13 to the MNP surface can be used to control CSA13 toxicity and potentially toxicity of other cationic lipids using covalent immobilization on the nanoparticle surface. Recent data show that CSA-124 (thiolated derivative of CSA-13) binding to silver nanoparticles (SNP) via nonspecific interactions (thermodynamically favorable silversulfur bonding) caused 100 percent hemolysis at a concentration of $50 \mu \mathrm{g} / \mathrm{ml}$, which is 1.5 times higher compared to CSA-124 alone [49]. Our study indicates that CSA-13, at these same concentrations, covalently attached to MNPs caused $\sim 1 \%$ hemolysis. These data provide evidence that chemical adsorption of drugs onto nanoparticle surfaces decreases hemolysis. Thus, we show the advantage of covalent binding compared with non-specific chemical adsorption. Ruden et al. reported that increasing the concentration of silver ions in combination with various antimicrobial peptides enhanced antibacterial activity. However, the combination of those peptides with silver nanoparticles did not increase hemolysis [50]. Another study indicated that RBCs exposed to gold coated magnetic nanoparticles induces hemolysis rates of under 5\% [51]. Similarly, encapsulation of daunorubicin on selfassembled iron oxide magnetic nanoparticles presented good hemocompatibility, with a hemolysis rate less than $5 \%$ [52]. Thus, stable immobilization of drugs, including synthetic analogs of antimicrobial peptides, onto a nanomaterial could be a method to overcome their limitations and side effects. Considering recent data that indicate some limitation for ceragenin use in systemic application [28], the antibacterial effect of MNP-CSA-13 was assessed
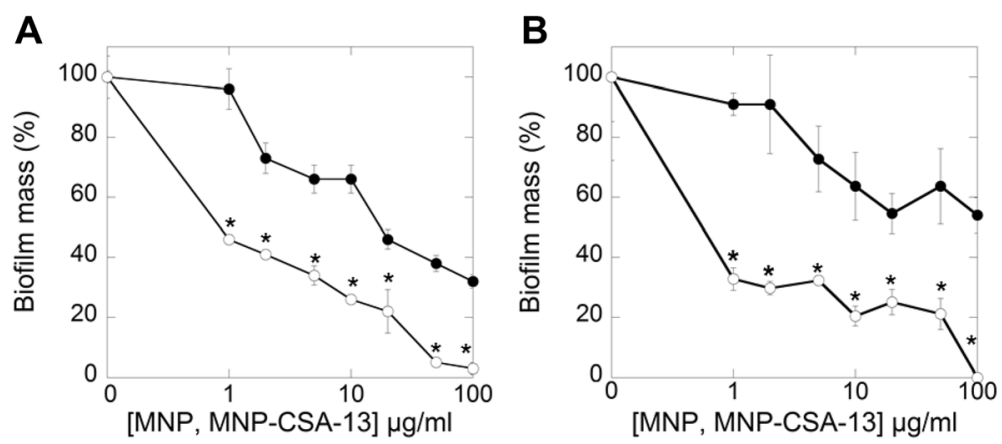

Figure 6 MNP-CSA-13 activity against bacteria biofilm formation. Bactericidal activity of MNPs (black circles) and MNP-CSA-13 (white circles) against biofilm forming $P$. aeruginosa PA01 (panel A) and P. aeruginosa clinical strain (panel B). Panels $\mathbf{A}$ and $\mathbf{B}$ represent effective killing of bacteria embedded in biofilm. Results represent mean \pm SD obtained from 3 experiments. ${ }^{*}$ statistical significance compared to bacteria treated with unfunctionalized MNPs. 

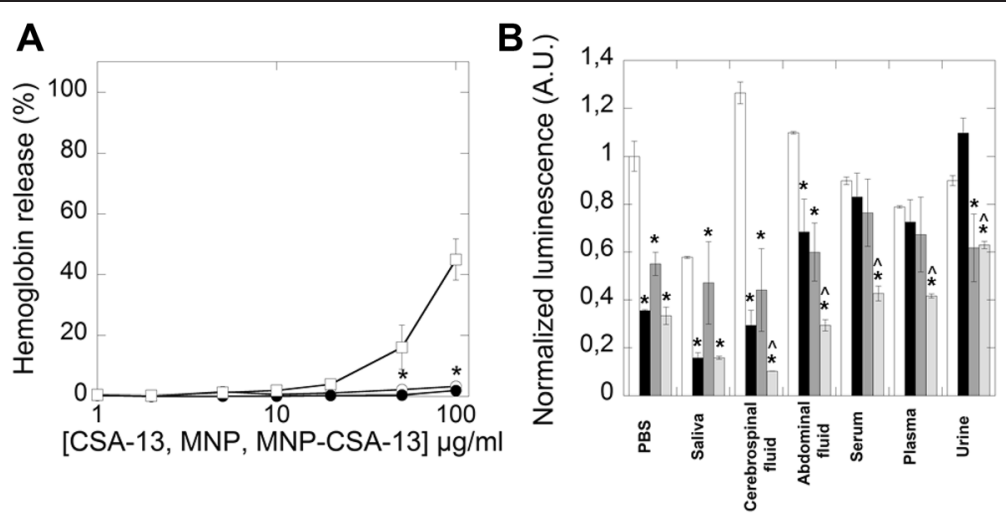

Figure 7 Biocompatibility and antibacterial activity of MNP-CSA-13 in different body fluids. Hemoglobin release from human red blood cells (RBCs) after CSA-13 (white squares), MNP (white circles) and MNP-CSA-13 (black circles) addition (panel A). Antibacterial activity of MNP-CSA-13 against Pseudomonas aeruginosa Xen 5 in different human body fluids assessed using chemiluminescence measurement (panel B). In each condition the white column indicates luminescence of control samples. The black column indicates the luminescence signal after free ceragenin CSA-13 (100 $\mu \mathrm{g} / \mathrm{ml})$ treatment. The gray column indicates luminescence signal after addition of MNPs $(100 \mu \mathrm{g} / \mathrm{ml})$. Light gray column show luminescence signal after addition of MNP-CSA-13. Results represent mean $\pm S D, n=3$; * statistical significance compared to untreated control, $\wedge$ compared to bacteria treated with $\operatorname{CSA}-13(p \leq 0.05)$.

against luminescence of $P$. aeruginosa Xen 5 in PBS containing $50 \%$ of different body fluids (Figure 7B). A significant decrease of bacterial luminescence was observed after addition of CSA-13, MNP and MNP@CSA-13 to cerebrospinal fluid, abdominal fluid and blood plasma specimens. Moreover, we observed that MNP-CSA-13 activity was higher than activity of CSA-13. It was also noted that free and functionalized CSA-13 possess the ability to bind bacterial membranes. Rapid interaction between $P$. aeruginosa cells and CSA-13 labeled with a fluorescent probe - BODIPY-succinimidyl ester (CSA-119) was recently reported. This study underlines the high affinity that positively charged ceragenins have for negatively charged bacterial membranes [39]. In agreement with reported results, we observed that ceragenin functionalized
MNPs possess positive zeta potential $(+39 \mathrm{eV})$ promoting the interaction with bacterial membrane surface characterized by negative zeta potential $(-15 \mathrm{eV})$. Additionally after MNP@CSA-13 addition to bacteria suspension, a change of zeta potential from $-15 \mathrm{eV}$ to $-6 \mathrm{eV}$ was observed. In agreement with our results, Thill et al. revealed that cationic charged nanoparticles interact with negatively charged bacterial membranes via electrostatic interaction [53].

To confirm the antibacterial activity of ceragenin functionalized magnetic nanoparticles we utilized atomic force microscopy (AFM) to identify changes in cell morphology and mechanical properties of $P$. aeruginosa upon MNP-CSA-13 treatment (Figure 8). The results indicate that MNP-CSA-13 adhered to bacteria and then
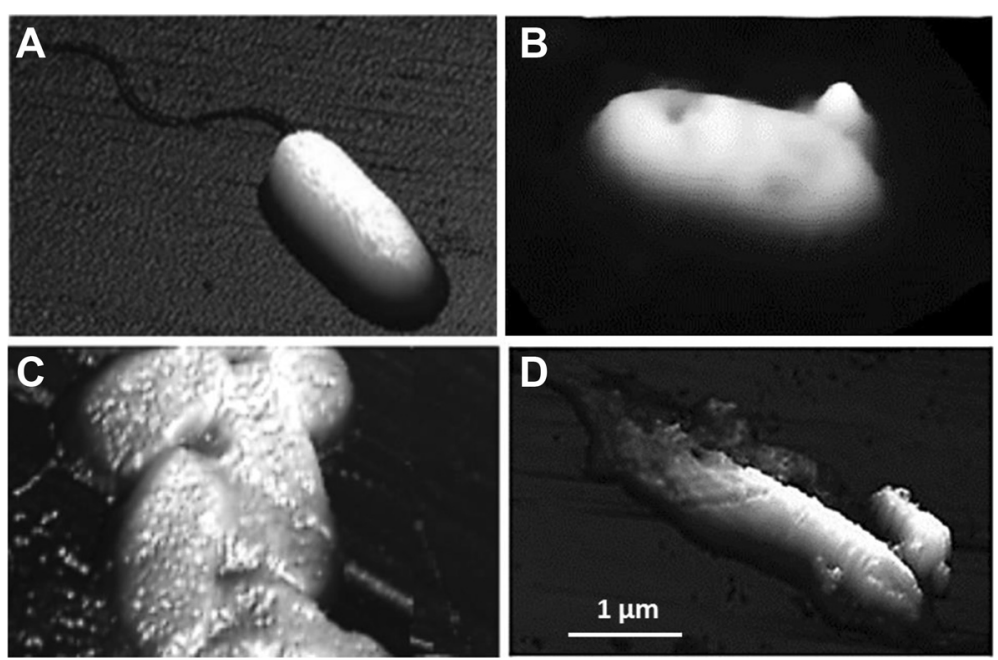

Figure 8 P. aeruginosa cell disruption under MNP-CSA-13 treatment, evaluated using atomic force microscopy. Images recorded before (A) and after CSA-13 (B), MNP (C) and MNP-CSA-13 (D) addition. Analysis of cell surface topography showed increasing membrane roughness and leakage of the intracellular contents. 
disrupted the cell membrane with leakage of the intracellular contents. Addition of unfunctionalized MNPs changes the bacterial shape and induce bacteria aggregation. Similarly to our finding De et al. revealed increases in membrane premeability of $P$. aeruginosa cells after treatment with lanthanium calcium manganate nanoparticles [54]. Disorganization of Gram-negative bacteria membranes was also confirmed for zinc oxide nanoparticles [55]. Additionally, our previous report indicates that magnetic nanoparticles possess the ability to aggregate $P$. aeruginosa cells due to interaction with their cell-wall component [25]. Combining CSA-13 antibacterial potential with the magnetic properties of MNP may have prospects for in vivo applications as a contrast in magnetic resonance imagining and novel tool to monitor infection sites in real-time. In a recent study the use of MNP in magnetic resonance imaging was explored [2], and compared to the MNP in the study the nanosystem presented in this work shows higher stability due to covalent CSA immobilization and possibility of controlled release of CSA-13, depending on the environmental $\mathrm{pH}$ [2]. However, the potential as a contrast agent needs to be explored in further studies.

\section{Conclusion}

Presented results suggest a promising future for the use of nanoparticles functionalized by antimicrobial cationic lipids in biomedical applications as drug carriers in a controlled drug delivery system. The MNP-CSA-13 nanoparticles demonstrate dual benefits: a decrease of ceragenin hemolytic activity and increase of antimicrobial properties in body fluids. Furthermore, these functionalized MNPs demonstrate the utility of a platform for creating a multitask nanosystem, which can be useful in theranostic applications.

\section{Methods \\ Synthesis of magnetic nanoparticles functionalized by CSA-13 (MNP-CSA-13)}

Iron oxide magnetic nanoparticles (MNP) were synthesized via modification of Massart's methods [16]. The shell around the magnetic core was obtained via polycondensation of 3-aminopropylotrimethoxy silane, then the nanoparticles were suspended in ethanol and glutaraldehyde was added. After 60 minutes of stirring at room temperature, the precipitate was isolated by magnetic decantation. The collected precipitate was washed with ethanol. In the final step, MNPs functionalized by glutaraldehyde were re-suspended in ethanol containing CSA-13 and sonicated for $1 \mathrm{~h}$. The precipitate was isolated by an external magnetic field, then washed three times with ethanol, three times with PBS and dried to powder at $60^{\circ} \mathrm{C}$.

\section{Nanoparticle characterization}

FT-IR spectra were recorded using a Thermo Scientific Nicolet 6700 FT-IR spectrophotometer. A thin layer of sample was placed in direct contact with an infrared attenuated total reflection (ATR) diamond crystal. All FT-IR spectra were collected in the wavenumber range of 4000 to $500 \mathrm{~cm}^{-1}$ by co-adding 32 scans with a resolution of $4 \mathrm{~cm}$ ${ }^{-1}$. Differential scanning calorimetry (DSC) was performed on a Mettler Toledo Star DSC system. Nitrogen was used as a purge gas $\left(10 \mathrm{ml} \cdot \mathrm{min}^{-1}\right)$. Samples between 2 and $5 \mathrm{mg}$ were placed in aluminum pans and heated from 25 to $450^{\circ} \mathrm{C}$ with a heating rate of $20^{\circ} \mathrm{C} / \mathrm{min}$. Thermogravimetric analysis (TGA) was recorded using a Mettler Toledo Star TGA/DSC unit. Nanoparticles (1-2 mg) were placed in the aluminum pans $(40 \mu \mathrm{l})$ and heated from 50 to $800^{\circ} \mathrm{C}$ with a heating rate of $10^{\circ} \mathrm{C} / \mathrm{min}$. The morphology of MNPs was studied with transmission electron microscopy TEM/EDX (Tecnai G2 X-TWIN). A drop of the nanoparticle dispersion in THF was deposited onto a carbon-coated copper grid and dried in a vacuum oven at temperature $50^{\circ} \mathrm{C}$.

\section{Quantitative analysis of CSA-13's presence on MNP surface}

As shown previously, the total number of amine groups present at the MNP surface in the MNPs@NH $\mathrm{N}_{2}$ sample, determined by acid-base titration, was $0.42 \mathrm{mmol} \mathrm{g}^{-1}$ [56]. The total amount of CSA-13 on the MNPs was estimated based on weight loss during TGA analysis.

\section{Release of ceragenin from MNP-CSA-13}

In order to determine the percentage of CSA-13 release in an in vitro setting, $10 \mu \mathrm{l}$ of MNP-CSA-13 nanoparticles $(10 \mathrm{mg} / \mathrm{ml})$ were suspended into $10 \mathrm{ml}$ of PBS $\left(140 \mathrm{mM} \mathrm{NaCl}, 7.5 \mathrm{mM} \mathrm{Na}_{2} \mathrm{HPO}_{4} ; \mathrm{pH} \sim 7.4\right)$ at $\mathrm{pH}=7.4$ and 5 respectively. In both environments, the cumulative amount of ceragenin released into the solution was measured by surface tension at different time intervals using the du Noüy ring method [57]. The surface tension was calculated from the radius of the ring and the tear-off force [57].

\section{Measure of the zeta potential of Pseudomonas aeruginosa cells and MNP-CSA-13}

The zeta potential measurements on $P$. aeruginosa were taken at $25^{\circ} \mathrm{C}$ on a Zetasizer Nano ZS (Malvern Instruments, UK) apparatus, which is based on electrophoretic light scattering. Attenuation selection, voltage selection and measurement duration were set as automatic. The quality of the measurements was evaluated by inspection of the phase plot. Overnight cultures of bacteria were adjusted to 0.1 absorbance $(600 \mathrm{~nm})$ in PBS buffer $(\mathrm{pH}=7.0)$. MNP-CSA-13 was dispersed in PBS buffer at concentration $2.5 \mathrm{mg} / \mathrm{ml}$. The assay was performed three times. 


\section{Antimicrobial testing}

To compare the bactericidal activities of CSA-13 $(0.7 \mu \mathrm{g} / \mathrm{ml})$ and MNP-CSA-13 $(5 \mu \mathrm{g} / \mathrm{ml})$ and MNPs themselves $(4.3 \mu \mathrm{g} / \mathrm{ml})$ against $P$. aeruginosa PAO14, killing assay/CFU counting method was performed [58]. The concentrations of tested agents were calculated to added equal amount of free CSA-13 and CSA-13 molecules attached to the MNP surface. Briefly, $P$. aeruginosa was grown to mid-log phase at $37^{\circ} \mathrm{C}$, re-suspended in PBS, and brought to $10^{8} \mathrm{CFU} / \mathrm{ml}$ (with the assumption that an optical density at $600 \mathrm{~nm}$ of 0.35 corresponds to $10^{8} \mathrm{CFU} / \mathrm{ml}$ ). They were then diluted in PBS containing different concentrations of CSA-13, MNPs or MNPCSA-13. After $1 \mathrm{~h}$ of incubation at $37^{\circ} \mathrm{C}$ the plates were transferred to ice and suspensions were diluted 10- to 1000 -fold in PBS. Then, $10 \mu \mathrm{l}$ aliquots were spotted on cetrimide-containing agar plates for overnight culture at $37^{\circ} \mathrm{C}$, then CFUs were determined. In other set of experiment changes of chemiluminescence intensity of $\mathrm{P}$. aeruginosa Xen5 after treatment with COL - colistin, CSA-13, MNP and MNP-CSA-13 measurements were determined as an additional method to assess bacteria viability. Chemiluminescence was evaluated using Labsystems Varioscan Flash (Thermo Scientific).

\section{MNP-CSA-13 activity against bacteria biofilm formation}

A biofilm of $P$. aeruginosa was grown for $48 \mathrm{~h}$ at $37^{\circ} \mathrm{C}$ with and without the antibacterial agents. Each well was washed four times with deionized water to remove planktonic bacteria. Biofilm mass was evaluated using crystal violet $(\mathrm{CV})$ staining (0.1\%). Excess stain was rinsed off with deionized water and plates were dried. Then, $100 \mu$ l ethanol was added and optical density (OD) was determined at a wavelength of $570 \mathrm{~nm}$. These OD values were considered as an index of bacteria adhering to the surface and forming a biofilm.

\section{Hemolytic activity}

MNPs, CSA-13 and MNP-CSA-13 hemolytic activity was tested using human red blood cells (RBCs) suspended in phosphate-buffered saline (PBS) (hematocrit $\sim 5 \%$ ) with a concentration of tested antibacterial agents ranging from $0-100 \mu \mathrm{g} / \mathrm{ml}$. RBCs were incubated with tested agents for $1 \mathrm{~h}$ at $37^{\circ} \mathrm{C}$. Relative hemoglobin concentration in supernatants after centrifugation at $2500 \mathrm{~g}$ was monitored by measuring optical absorbance at $540 \mathrm{~nm} .100 \%$ hemolysis was taken from samples in which $1 \%$ Triton X-100 was added to disrupt all cell membrane.

\section{Antimicrobial activity of MNP-CSA-13 in different body fluids}

To assess the ability of MNP, MNP-CSA-13 and free CSA13 to kill bacteria in different compartments of the human body, changes of $P$. aeruginosa Xen 5 chemiluminescence
( $10^{9} \mathrm{CFU} / \mathrm{ml}$ ) in PBS mixed with $50 \%$ human blood plasma, serum, cerebrospinal fluid, peritoneal fluid, saliva and urine were assessed [28]. The luminomeric curves were recorded during 30 minutes after its addition.

\section{AFM imagining}

AFM images were taken using an AFM BioScope Catalyst (LABSOFT, Bruker Nano Surfaces Division, Santa Barbara, USA). All measurements were performed in air-dried samples. The data was processed using NanoScope ${ }^{\oplus}$ AFM software.

\section{Abbreviations}

AFM: Atomic force microscopy; AMPs: Antimicrobial peptides; APTMS: 3-aminopropylotrimethoxy silane; CAPs: Cationic antibacterial peptides; CSA: Ceragenins; CV: Crystal violet; DDS: Drug delivery systems; DSC: Differential scanning calorimetry; GDl: Glutaraldehyde; MNP@NH = $\mathrm{CH}\left(\mathrm{CH}_{2}\right)_{3} \mathrm{CHO}$ : Glutaraldehyde functionalized magnetic nanoparticles; MNP@NH 2 : Magnetic nanoparticles coated by aminosilane; MNP-CSA-13: Ceragenins functionalized magnetic nanoparticles; MNPs: Magnetic nanoparticles; TEM: Transmission electron microscopy; TGA: Thermogravimetric analysis.

\section{Competing interests}

In 2012, Dr R. Bucki was involved in a sponsored research agreement with Genentech in a project directed at evaluating the potential clinical use of p-ASP to improved Pulmozyme activity, but not otherwise related to the present study. Other authors: none to declare. None of the research reported in this paper was supported by any corporate entity.

\section{Authors' contributions}

$\mathrm{KN}$ : participated in study design, synthesis of magnetic nanoparticles, evaluation of nanoparticles and CSA bactericidal activity in different settings, helped to draft the manuscript; US: carried out biofilm studies, helped to draft the manuscript; AW: evaluation of physicochemical properties of magnetic nanoparticles, helped to draft the manuscript; JM: evaluation of physicochemical properties of nanoparticles; EP: evaluation of nanoparticles and CSA activity against host cells, helped to draft the manuscript; XG: CSAs synthesis and helped to draft the manuscript; ZN; perform specimens collection and helped to draft the manuscript; AK: collected and analyzed data, helped to draft the manuscript; PS: synthesis of different CSAs, helped to draft the manuscript; RB: study design, carried out evaluation of MNP@CSA activity in presence of body fluids, helped to draft the manuscript, supervised the project. All authors discussed the results and implications and commented on the manuscript at all stages.

\section{Acknowledgements}

This work was financially supported by the National Science Centre, Poland, Grants UMO-2012/07/B/NZ6/03504 (to R. Bucki) and UMO-2012/05/N/NZ7/ 00534 (to K. Niemirowicz). Authors also acknowledge the Leading National Research Centre (project number: 27/KNOW/2013). The equipment used for analysis in the Center of Synthesis and Analysis BioNanoTechno of University of Bialystok was funded by EU, as part of the Operational Program Development of Eastern Poland 2007-2013, project: POPW.01.03.00-20-034/09-00. We are grateful to Ms. Karolina H. Markiewicz (FTIR) and Ms. Iwona Misztalewska (TEM) for facilitating this study.

\section{Author details}

${ }^{1}$ Department of Microbiological and Nanobiomedical Engineering, Medical University of Bialystok, Mickiewicza 2c, 15-222 Bialystok, Poland. ${ }^{2}$ Institute of Chemistry, University of Bialystok, 1 Hurtowa, 15-399 Bialystok, Poland. ${ }^{3}$ Department of Materials and Biomedical Engineering, Białystok University of Technology, 15-351 Białystok, Poland. ${ }^{4}$ Department of Physiology, Medical University of Białystok, 15-230 Białystok, Poland. ${ }^{5}$ Department of Neurology, Medical University of Bialystok, 15-230 Bialystok, Poland. ${ }^{6}$ Department of Chemistry and Biochemistry, Brigham Young University, Provo, UT, USA. ${ }^{7}$ Department of Physiology, Pathophysiology and Microbiology of Infections, The Faculty of Health Sciences of the Jan Kochanowski University in Kielce, 25-317 Kielce, Poland. 
Received: 22 January 2015 Accepted: 23 April 2015

Published online: 01 May 2015

\section{References}

1. Chin JN, Jones RN, Sader HS, Savage PB, Rybak MJ. Potential synergy activity of the novel ceragenin, CSA-13, against clinical isolates of Pseudomonas aeruginosa, including multidrug-resistant $P$. aeruginosa. J Antimicrob Chemother. 2008;61(2):365-70

2. Hoppens MA, Wheeler ZE, Qureshi AT, Hogan K, Wright A, Stanley GG, et al. Maghemite, silver, ceragenin conjugate particles for selective binding and contrast of bacteria. J Colloid Interface Sci. 2014;413:167-74.

3. Isogai E, Isogai H, Takahashi K, Okumura K, Savage PB. Ceragenin CSA-13 exhibits antimicrobial activity against cariogenic and periodontopathic bacteria. Oral Microbiol Immunol. 2009;24(2):170-2.

4. Kuroda $K$, Fukuda $T$, Okumura $K$, Yoneyama $H$, Isogai $H$, Savage $P B$, et al. Ceragenin CSA-13 induces cell cycle arrest and antiproliferative effects in wild-type and p53 null mutant HCT116 colon cancer cells. Anticancer Drugs. 2013;24(8):826-34

5. Polat ZA, Savage PB, Genberg C. In vitro amoebicidal activity of a ceragenin, cationic steroid antibiotic-13, against Acanthamoeba castellanii and its cytotoxic potential. J Ocul Pharmacol Ther. 2011;27(1):1-5.

6. Howell MD, Streib JE, Kim BE, Lesley LJ, Dunlap AP, Geng D, et al. Ceragenins: a class of antiviral compounds to treat orthopox infections. J Invest Dermatol. 2009;129(11):2668-75.

7. Lai XZ, Feng Y, Pollard J, Chin JN, Rybak MJ, Bucki R, et al. Ceragenins: cholic acidbased mimics of antimicrobial peptides. Acc Chem Res. 2008;41(10):1233-40.

8. Van Bambeke F, Mingeot-Leclercq MP, Struelens MJ, Tulkens PM. The bacterial envelope as a target for novel anti-MRSA antibiotics. Trends Pharmacol Sci. 2008;29(3):124-34.

9. Wilczewska AZ, Niemirowicz K, Markiewicz KH, Car H. Nanoparticles as drug delivery systems. Pharmacol Rep. 2012;64(5):1020-37.

10. Giannaccini M, Giannini M, Calatayud MP, Goya GF, Cuschieri A, Dente L. Magnetic nanoparticles as intraocular drug delivery system to target retinal pigmented epithelium (RPE). Int J Mol Sci. 2013;15(1):1590-605.

11. Tate JA, Petryk AA, Giustini AJ, Hoopes PJ. In vivo biodistribution of iron oxide nanoparticles: an overview. Proc SPIE. 2011;7901:790117.

12. Singh RK, Patel KD, Kim JJ, Kim TH, Kim JH, Shin US et al. Multifunctional Hybrid Nanocarrier: Magnetic CNTs Ensheathed with Mesoporous Silica for Drug Delivery and Imaging System. ACS Appl Mater Interfaces; 2014; 6(4):2201-8

13. He X, Liu F, Liu L, Duan T, Zhang H, Wang Z. Lectin-conjugated Fe2O3@Au core@shell nanoparticles as dual mode contrast agents for in vivo detection of tumor. Mol Pharm. 2014; 11(3):738-45

14. Niemirowicz K, Markiewicz KH, Wilczewska AZ, Car H. Magnetic nanoparticles as new diagnostic tools in medicine. Adv Med Sci. 2012;57(2):196-207.

15. Dionigi C, Lungaro L, Goranov V, Riminucci A, Piñeiro-Redondo Y, Bañobre-López $\mathrm{M}$ et al. Smart magnetic poly(N-isopropylacrylamide) to control the release of bio-active molecules. J Mater Sci Mater Med. 2014; 25(10):2365-71.

16. Massart R. Preparation of aqueous magnetic liquids in alkaline and acidic media. IEEE Trans Magn. 1981;17(2):1247-8.

17. Całkosiński I, Dobrzyński M, Całkosińska M, Seweryn E, Bronowicka-Szydełko A, Dzierzba K, et al. [Characterization of an inflammatory response]. Postepy Hig Med Dosw (Online). 2009;63:395-408.

18. Kellum JA. Metabolic acidosis in patients with sepsis: epiphenomenon or part of the pathophysiology? Crit Care Resusc. 2004;6(3):197-203.

19. Brotman RM. Vaginal microbiome and sexually transmitted infections: an epidemiologic perspective. J Clin Invest. 2011;121(12):4610-7.

20. Bowler PG, Duerden BI, Armstrong DG. Wound microbiology and associated approaches to wound management. Clin Microbiol Rev. 2001;14(2):244-69.

21. Fu Y, Kao WJ. Drug release kinetics and transport mechanisms of non-degradable and degradable polymeric delivery systems. Expert Opin Drug Deliv. 2010;7(4):429-44.

22. Leszczyńska K, Namiot A, Fein DE, Wen Q, Namiot Z, Savage PB, et al. Bactericidal activities of the cationic steroid CSA-13 and the cathelicidin peptide LL-37 against Helicobacter pylori in simulated gastric juice. BMC Microbiol. 2009;9:187.

23. Huang $X$, Brazel CS. On the importance and mechanisms of burst release in matrix-controlled drug delivery systems. J Control Release. 2001;73(2-3):121-36.

24. Hussein-Al-Ali SH, El Zowalaty ME, Hussein MZ, Ismail M, Webster TJ. Synthesis, characterization, controlled release, and antibacterial studies of a novel streptomycin chitosan magnetic nanoantibiotic. Int J Nanomedicine. 2014;9:549-57.
25. Niemirowicz K, Swiecicka I, Wilczewska AZ, Misztalewska I, Kalska-Szostko B, Bienias K, et al. Gold-functionalized magnetic nanoparticles restrict growth of Pseudomonas aeruginosa. Int J Nanomedicine. 2014;9:2217-24.

26. Movahedi Z, Pourakbari B, Mahmoudi S, Sabouni F, Ashtiani Haghi MT, Hosseinpour Sadeghi R, et al. Pseudomonas aeruginosa infection among cystic fibrosis and ICU patients in the referral children medical hospital in Tehran, Iran. J Prev Med Hyg. 2013;54(1):24-8.

27. Trandafir LM, Moscalu M, Diaconu G, Cîrdeiu E, Tudose AA, Coman G, et al. The impact of respiratory tract infections on the nutritional state of children with cystic fibrosis. Rev Med Chir Soc Med Nat lasi. 2013;117(4):863-9.

28. Leszczyńska K, Namiot A, Cruz K, Byfield FJ, Won E, Mendez G, et al. Potential of ceragenin CSA-13 and its mixture with pluronic F-127 as treatment of topical bacterial infections. J Appl Microbiol. 2011;110(1):229-38.

29. Carmona-Ribeiro AM, de Melo Carrasco LD. Novel formulations for antimicrobial peptides. Int J Mol Sci. 2014;15(10):18040-83.

30. Thach $\mathrm{CV}$, Hai NH, Chau N. Size controlled magnetite nanoparticles and their drug loading ability. J Korean Phys Soc. 2008;52(5):1332-5.

31. Hussein-Al-Ali SH, El Zowalaty ME, Kura AU, Geilich B, Fakurazi S, Webster TJ, et al. Antimicrobial and controlled release studies of a novel nystatin conjugated iron oxide nanocomposite. Biomed Res Int. 2014;2014:651831.

32. Costa F, Carvalho IF, Montelaro RC, Gomes P, Martins MC. Covalent immobilization of antimicrobial peptides (AMPs) onto biomaterial surfaces. Acta Biomater. 2011;7(4):1431-40.

33. Zhao L, Chu PK, Zhang Y, Wu Z. Antibacterial coatings on titanium implants. J Biomed Mater Res B Appl Biomater. 2009;91(1):470-80.

34. Kierys A. Synthesis of Aspirin-loaded Polymer-Silica Composites and their Release Characteristics. ACS Appl Mater Interfaces; 2014;6(16):14369-76.

35. Cantón R, Fernández Olmos A, de la Pedrosa EG, del Campo R, Antonia Meseguer M. [Chronic bronchial infection: the problem of Pseudomonas aeruginosa]. Arch Bronconeumol. 2011;47 Suppl 6:8-13.

36. Cenvia JS, Ortolano GA, Canonica FP, McAlister MB. Role of biofilm in Pseudomonas aeruginosa colonization and infection. Infect Control Hosp Epidemiol. 2009;30(9):925-7

37. de Bentzmann S, Plésiat P. The Pseudomonas aeruginosa opportunistic pathogen and human infections. Environ Microbiol. 2011;13(7):1655-65.

38. Nagant C, Pitts B, Stewart PS, Feng Y, Savage PB, Dehaye JP. Study of the effect of antimicrobial peptide mimic, CSA-13, on an established biofilm formed by Pseudomonas aeruginosa. Microbiologyopen. 2013;2(2):318-25.

39. Nagant C, Feng Y, Lucas B, Braeckmans K, Savage P, Dehaye JP. Effect of a low concentration of a cationic steroid antibiotic (CSA-13) on the formation of a biofilm by Pseudomonas aeruginosa. J Appl Microbiol. 2011;111(3):763-72.

40. Leuba KD, Durmus NG, Taylor EN, Webster TJ. Short communication: carboxylate functionalized superparamagnetic iron oxide nanoparticles (SPION) for the reduction of S. aureus growth post biofilm formation. Int J Nanomedicine. 2013;8:731-6.

41. Sathyanarayanan MB, Balachandranath R, Genji Srinivasulu Y, Kannaiyan SK, Subbiahdoss $G$. The effect of gold and iron-oxide nanoparticles on biofilm-forming pathogens. ISRN Microbiol. 2013;2013:272086.

42. Hetrick EM, Shin JH, Paul HS, Schoenfisch MH. Anti-biofilm efficacy of nitric oxide-releasing silica nanoparticles. Biomaterials. 2009;30(14):2782-9.

43. Abdelghany SM, Quinn DJ, Ingram RJ, Gilmore BF, Donnelly RF, Taggart CC, et al. Gentamicin-loaded nanoparticles show improved antimicrobial effects towards Pseudomonas aeruginosa infection. Int J Nanomedicine. 2012;7:4053-63.

44. Hiemstra PS. Antimicrobial peptides in the real world: implications for cystic fibrosis. Eur Respir J. 2007;29(4):617-8.

45. Sieprawska-Lupa M, Mydel P, Krawczyk K, Wójcik K, Puklo M, Lupa B, et al. Degradation of human antimicrobial peptide LL-37 by Staphylococcus aureus-derived proteinases. Antimicrob Agents Chemother. 2004;48(12):4673-9.

46. Glukhov E, Burrows LL, Deber CM. Membrane interactions of designed cationic antimicrobial peptides: the two thresholds. Biopolymers. 2008:89(5):360-71.

47. Bucki R, Sostarecz AG, Byfield FJ, Savage PB, Janmey PA. Resistance of the antibacterial agent ceragenin CSA-13 to inactivation by DNA or F-actin and its activity in cystic fibrosis sputum. J Antimicrob Chemother. 2007:60(3):535-45.

48. Drašler B, Drobne D, Novak S, Valant J, Boljte S, Otrin L, et al. Effects of magnetic cobalt ferrite nanoparticles on biological and artificial lipid membranes. Int J Nanomedicine. 2014;9:1559-81. 
49. Machen TJ, Hoppens MA, Qureshi AT, Hayes DJ. The hemocompatibility of the synthetic antimicrobial compound CSA-124 and CSA-124 bound to silver nanoparticles. 2014

50. Ruden S, Hilpert K, Berditsch M, Wadhwani P, Ulrich AS. Synergistic interaction between silver nanoparticles and membrane-permeabilizing antimicrobial peptides. Antimicrob Agents Chemother. 2009;53(8):3538-40.

51. Li Y, Liu J, Zhong Y, Zhang J, Wang Z, Wang L, et al. Biocompatibility of $\mathrm{Fe}_{3} \mathrm{O}_{4} @ \mathrm{Au}$ composite magnetic nanoparticles in vitro and in vivo. Int J Nanomedicine. 2011;6:2805-19.

52. Wu W, Chen B, Cheng J, Wang J, Xu W, Liu L, et al. Biocompatibility of Fe3O4/DNR magnetic nanoparticles in the treatment of hematologic malignancies. Int J Nanomedicine. 2010;5:1079-84.

53. Thill A, Zeyons O, Spalla O, Chauvat F, Rose J, Auffan M, et al. Cytotoxicity of $\mathrm{CeO} 2$ nanoparticles for Escherichia coli. Physico-chemical insight of the cytotoxicity mechanism Environ Sci Technol. 2006;40(19):6151-6.

54. De D, Mandal SM, Gauri SS, Bhattacharya R, Ram S, Roy SK. Antibacterial

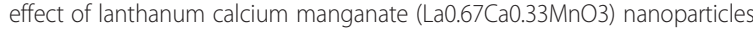
against Pseudomonas aeruginosa ATCC 27853. J Biomed Nanotechnol. 2010;6(2):138-44

55. Brayner R, Ferrari-lliou R, Brivois N, Djediat S, Benedetti MF, Fiévet F. Toxicological impact studies based on Escherichia coli bacteria in ultrafine $\mathrm{ZnO}$ nanoparticles colloidal medium. Nano Lett. 2006;6(4):866-70.

56. Wilczewska A, Markiewicz K. Surface-initiated RAFT/MADIX polymerization on xanthate-coated iron oxide nanoparticles. Macromol Chem Phys. 2014;215(2):190-7.

57. du Noüy PL. An interfacial tensiometer for universal use. J Gen Physiol. 1925;7(5):625-31.

58. Bucki R, Leszczynska K, Byfield FJ, Fein DE, Won E, Cruz K, et al. Combined antibacterial and anti-inflammatory activity of a cationic disubstituted dexamethasone-spermine conjugate. Antimicrob Agents Chemother. 2010;54(6):2525-33.

\section{Submit your next manuscript to BioMed Central and take full advantage of:}

- Convenient online submission

- Thorough peer review

- No space constraints or color figure charges

- Immediate publication on acceptance

- Inclusion in PubMed, CAS, Scopus and Google Scholar

- Research which is freely available for redistribution 